\title{
Brain Development in Fetuses of Mothers with Diabetes: A Case-Control MR Imaging Study
}

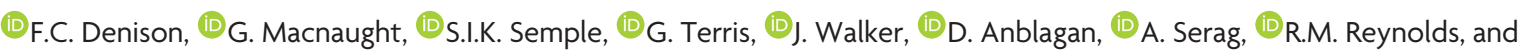
(D).P. Boardman

\begin{abstract}
BACKGROUND AND PURPOSE: Offspring exposed to maternal diabetes are at increased risk of neurocognitive impairment, but its origins are unknown. With MR imaging, we investigated the feasibility of comprehensive assessment of brain metabolism ('H-MRS), microstructure (DWI), and macrostructure (structural MRI) in third-trimester fetuses in women with diabetes and determined normal ranges for the MR imaging parameters measured.
\end{abstract}

MATERIALS AND METHODS: Women with singleton pregnancies with diabetes $(n=26)$ and healthy controls $(n=26)$ were recruited prospectively for MR imaging studies between 34 and 38 weeks' gestation.

RESULTS: Data suitable for postprocessing were obtained from $79 \%, 71 \%$, and $46 \%$ of women for ${ }^{1} \mathrm{H}-\mathrm{MRS}$, DWI, and structural MRI, respectively. There was no difference in the NAA/Cho and NAA/Cr ratios (mean [SD]) in the fetal brain in women with diabetes compared with controls (1.74 [0.79] versus 1.79 [0.64], $P=.81$; and 0.78 [0.28] versus $0.94[0.36], P=.12$, respectively), but the Cho/Cr ratio was marginally lower $(0.46[0.11]$ versus $0.53[0.10], P=.04)$. There was no difference in mean [SD] anterior white, posterior white, and deep gray matter ADC between patients and controls $(1.16[0.12]$ versus $1.16[0.08], P=.96 ; 1.54[0.16]$ versus $1.59[0.20], P=.56 ;$ and 1.49 [0.23] versus 1.52 [0.23], $P=.89$, respectively) or volume of the cerebrum $(243.0 \mathrm{~mL}[22.7 \mathrm{~mL}]$ versus $253.8 \mathrm{~mL}[31.6 \mathrm{~mL}], P=.38)$.

CONCLUSIONS: Acquiring multimodal MR imaging of the fetal brain at 3 T from pregnant women with diabetes is feasible. Further study of fetal brain metabolism in maternal diabetes is warranted.

ABBREVIATIONS: TIDM = type 1 diabetes mellitus; T2DM = type 2 diabetes mellitus; GDM = gestational diabetes; sMRI = structural MRI

D abetes is the most common medical disorder of pregnancy with the prevalence of type 1 (T1DM), type 2 (T2DM), and gestational diabetes (GDM) all increasing among women of childbearing age in resource-rich settings. The perinatal complications of maternal diabetes, which reflect altered metabolic function in utero, include major congenital malformations, macrosomia, and stillbirth. ${ }^{1}$ Long-term, children born to mothers with diabetes are

Received September 28, 2016; accepted December 20.

From the Medical Research Council Centre for Reproductive Health (F.C.D., D.A., A.S., J.P.B.), University of Edinburgh, Queen's Medical Research Institute, Edinburgh, UK; Clinical Research Imaging Centre (G.M., S.I.K.S.), University/British Heart Foundation Centre for Cardiovascular Science (S.I.K.S., R.M.R.), and Centre for Clinical Brain Sciences (D.A., J.P.B.), University of Edinburgh, Edinburgh, UK; and Simpson Centre for Reproductive Health (G.T., J.W.), Royal Infirmary, Edinburgh, UK.

This work was supported by Theirworld (www.theirworld.org) and was undertaken in the Medical Research Council Centre for Reproductive Health, which is funded by an Medical Research Council Centre grant (Medical Research Council G1002033). We acknowledge the support of the British Heart Foundation.

Please address correspondence to Fiona C. Denison, MD, Medical Research Council Centre for Reproductive Health, University of Edinburgh, Queen's Medical Research Institute, 47 Little France Crescent, Edinburgh EH16 4TJ, UK; e-mail: Fiona.Denison@ed.ac.uk; @MRC_CRH

http://dx.doi.org/10.3174/ajnr.A5118 at increased risk for cognitive impairment, ${ }^{2,3}$ inattentiveness, ${ }^{4}$ impaired working memory, ${ }^{5}$ and altered language development. ${ }^{6}$ These adverse outcomes are not fully explained by postnatal events; this question focuses research attention on the vulnerability of the developing brain during fetal life. Identification of the nature and timing of alterations to brain structure and function that underlie neurocognitive impairment could help the development of strategies designed to improve the long-term outcome of children of diabetic mothers.

During fetal life, the predominant source of brain energy is glucose, which crosses the placenta by facilitated diffusion. ${ }^{7}$ While severe perturbations in glucose homeostasis after birth are associated with neonatal brain injury, the effect of chronic fluctuant glucose concentration experienced by fetuses of women with diabetes on in utero brain development has not been investigated, to our knowledge. Maternal diabetes is also associated with disturbances in fatty acid metabolism: Umbilical venous blood docosahexaenoic acid concentration is reduced; this reduction reflects lower docosahexaenoic acid transfer to the fetus. ${ }^{8}$ Docosahexaenoic acid accumulates in the brain in abundance from the 
third trimester and is essential for neurogenesis, neurotransmission, and protection from oxidative stress. Reduced bioavailability of this key metabolite has been suggested as a putative mechanism for programming altered neurodevelopment. ${ }^{8,9}$

Advances in proton MR spectroscopy ( $\left.{ }^{1} \mathrm{H}-\mathrm{MRS}\right)$ and diffusion-weighted and structural MR imaging (sMRI) have led to the development of objective and sensitive measures of fetal brain structure and metabolism. Use of these technologies has revealed alterations in the cerebral NAA:choline ratio and gyrification in fetuses with congenital heart disease, ${ }^{10}$ temporal lobe volumes in fetuses with congenital cytomegalovirus infection, ${ }^{11}$ and ADC values and parenchymal volume in antenatal ventriculomegaly. ${ }^{12,13}$ Historically, most fetal imaging studies have been undertaken at 1.5T. However, although an increasing number of studies have been performed at 3T field strength, ${ }^{14-20}$ which has benefits over $1.5 \mathrm{~T}$ due to improved signal-to-noise and is likely to be advantageous for depicting fetal anatomy, ${ }^{21}$ to date, there have been no studies assessing the feasibility of recruiting women with diabetes for fetal neuroimaging.

Early-life metrics derived from ${ }^{1} \mathrm{H}-\mathrm{MRS}$, DWI, and sMRI are associated with function in childhood. After preterm birth, $\mathrm{NAA} / \mathrm{Cho}$ and $\mathrm{Cho} / \mathrm{Cr}$ ratios are associated with neurodevelopmental outcome at 2 years of age, ${ }^{22}$ lactate/NAA predicts outcome following hypoxic-ischemic encephalopathy, ${ }^{23}$ and abnormalities in the NAA/Cr and Cho/Cr ratios in neonates ${ }^{24}$ and older children $^{25}$ predict developmental delay. Increased ADC values in white matter are associated with diffuse white matter injury following preterm birth ${ }^{26}$ and with poor outcome after hypoxicischemic encephalopathy in term infants. ${ }^{27,28}$ Finally, reduced regional and whole-brain volumes are associated with specific preterm comorbidities, ${ }^{29,30}$ and structural alteration predicts long-term impairment after preterm birth. ${ }^{31,32}$

On the basis of disturbances to fetal glucose and fatty acid metabolism associated with maternal diabetes and the neurocognitive profile of offspring, we aimed to investigate the feasibility of comprehensive fetal brain assessment by acquiring measurements of NAA/Cho, NAA/Cr, and Cho/Cr ratios; regional apparent diffusion coefficient measurements; and volume of the cerebrum during the third trimester of pregnancy from women with diabetes and from healthy controls by using $3 \mathrm{~T}$ MR imaging. The secondary aim was to determine normal values for these measures for future studies designed to investigate the effect of maternal disease on fetal brain development and in utero origins of neurodevelopmental impairment.

\section{MATERIALS AND METHODS \\ Study Population}

Ethics approval was obtained from the National Research Ethics Committee (South East Scotland Research Ethics Committee), and written informed consent was obtained. Women with a pregnancy complicated by diabetes $(n=26)$ and healthy controls $(n=$ 26) were recruited prospectively from antenatal diabetes clinics at the Simpson Centre for Reproductive Health at the Royal Infirmary, Edinburgh, UK. The inclusion criteria were a singleton pregnancy and a fetal anomaly scan with normal findings at 20 weeks' gestation. Women with diabetes were eligible to participate if they had gestational diabetes, diagnosed by using the Scottish Intercollegiate Guideline Network diagnostic criteria ${ }^{33}$ as a fasting venous plasma glucose of $\geq 5.1 \mathrm{mmol} / \mathrm{l}$ or 2 -hour glucose of $\geq 8.5 \mathrm{mmol} / \mathrm{l}$ after a 75 -g oral glucose tolerance test or pregestational type 1 or type 2 diabetes. Exclusion criteria were serious coexisting maternal systemic disease other than maternal diabetes and women with any contraindications to MR imaging, including metal implants and pacemakers.

\section{MR Image Acquisition}

MR imaging studies were performed at the Clinical Research Imaging Centre in the Queen's Medical Research Institute, University of Edinburgh, UK, by using a Magnetom Verio 3T MR imaging clinical scanner (Siemens, Erlangen, Germany). To avoid vena-cava compression, we placed women in a left-lateral tilt, with blood pressure being constantly monitored by using a Veris MR imaging vital signs monitor (Medrad, Indianola, Pennsylvania). No fetal sedation was used, women were limited to spending 45 minutes in the scanner, and data were acquired with women free-breathing throughout. MR images were obtained between 34 and 38 weeks' gestation. A radiologist with experience in MR imaging reported all images.

T2-weighted half-Fourier-acquisition single-shot turbo spinecho images were acquired of the fetal brain in sagittal, coronal, and transverse orientations (HASTE: TR/TE $=1800 / 86 \mathrm{~ms}$, $\mathrm{FOV}=400 \times 400 \mathrm{~mm}$, matrix $=192$ [phase] $\times 256$ [frequency], section thickness $=8 \mathrm{~mm}$, acquisition time $=18$ seconds). These images were used to plan the position of the single $20-\mathrm{mm}^{3}$ spectroscopy voxel within the fetal brain. The scanner bed was moved to ensure that the fetal brain was positioned at the isocenter, and the voxel was positioned within 1 hemisphere of the fetal brain, avoiding ventricles and contaminant signal from surrounding tissue. An optimized semiautomated shimming protocol was systematically applied until the full width at half maximum of the water peak was $<20 \mathrm{~Hz}$. A single-voxel point-resolved spectroscopy technique was applied with TR/TE $=1500 / 30 \mathrm{~ms}$, 96 signal averages, bandwidth $=2000 \mathrm{~Hz}$, and a water suppression bandwidth $=50 \mathrm{~Hz}$. The spectral acquisition took 2 minutes $30 \mathrm{sec}-$ onds. Signal was received from selected elements of the spine matrix coil and body matrix surface coils positioned to allow adequate coverage of the fetal brain. A postspectroscopy 3-plane HASTE acquisition was then compared with the prespectroscopy HASTE images to allow visual assessment of fetal movement during the spectral acquisition. If the expert operator observed evidence of movement between HASTE acquisitions, then the spectroscopy voxel was repositioned and the spectral acquisition was repeated. No additional filtering or quality-control limiting of data was applied during the processing stage. We therefore processed all the MR spectroscopy data that were acquired. An example of voxel positioning for the MR spectroscopy acquisition is shown in Fig $1 A$.

Transverse DWIs of the whole fetal brain $(\mathrm{TR} / \mathrm{TE}=7300 / 106$ $\mathrm{ms}, \mathrm{FOV}=400 \times 400 \mathrm{~mm}$, matrix $=128 \times 128$, section thickness $=3 \mathrm{~mm}$, b-values $=0,500$, and $1000 \mathrm{~s} / \mathrm{mm}^{2}$ ) were acquired. DWI was checked at the point of acquisition for obvious signs of fetal motion and was repeated if required. ADC maps were generated automatically from the diffusion-weighted images.

Finally, additional transverse HASTE images were acquired with identical coverage to the DWIs to aid subsequent ROI anal- 

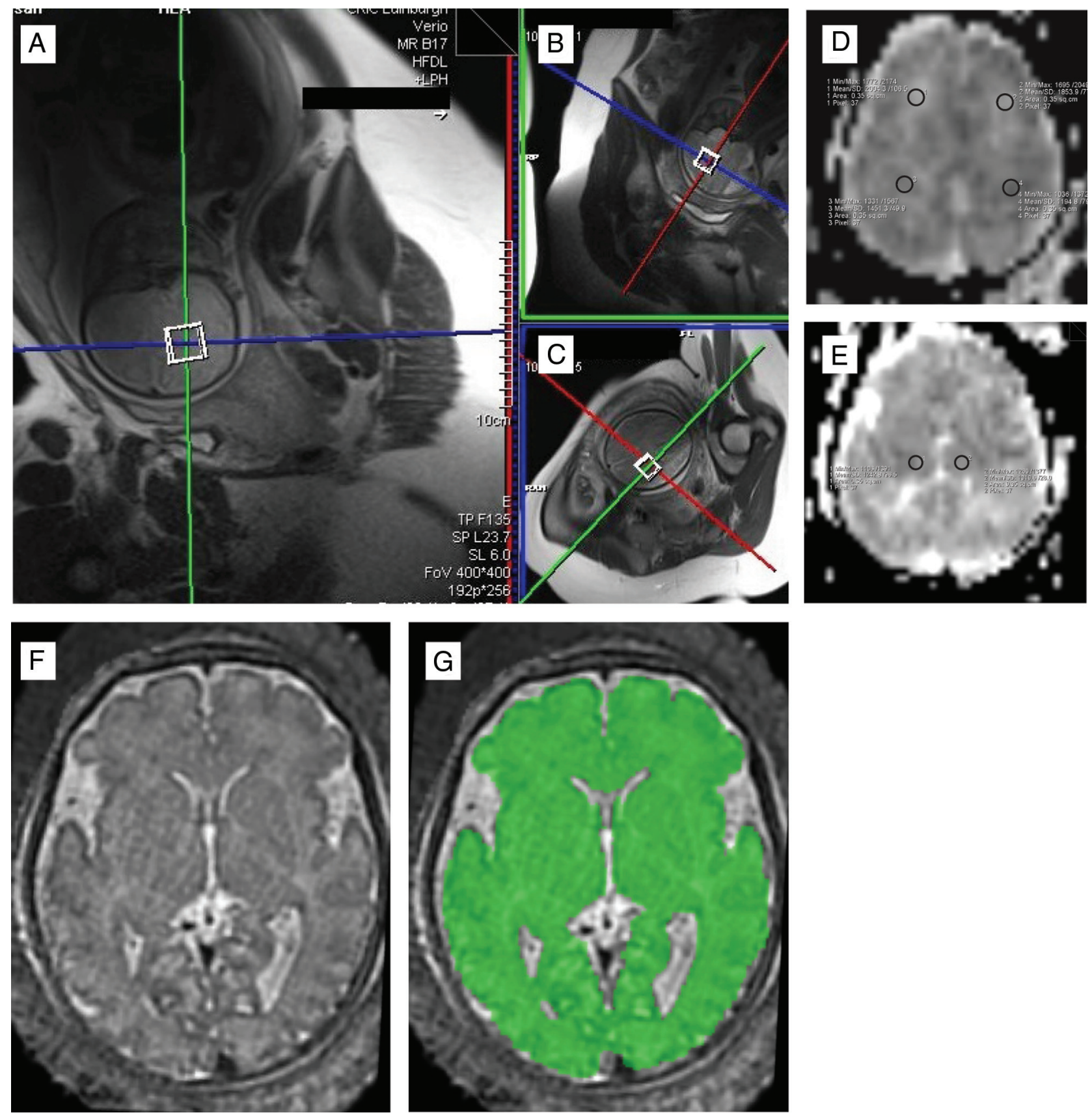

FIG 1. Examples of MR spectroscopy voxel placement in the fetal brain $(A-C)$. ROIs for DWI in anterior white matter and posterior white matter (right and left) $(D)$ and deep gray matter (right and left) (E), and tissue segmentation in the brain, highlighted in green $(F-G)$.

ysis and to enable construction of the $3 \mathrm{D}$ motion-corrected brain volumes.

\section{Data Analysis: ${ }^{\mathbf{H}} \mathrm{H}-\mathrm{MRS}$}

Spectral analysis was performed by using the QUEST algorithm available in jMRUI (www.mrui.uab.es/mrui/mrui_download/). ${ }^{34}$ This technique estimates metabolite amplitudes by using a nonlinear least-squares fit of simulated metabolite signals to the acquired spectrum. A metabolite basis set was generated by using the NMR-Scope function available in $\mathrm{jMRUI}^{35}$ and included contributions from NAA $(2.01,2.49$, and $2.70 \mathrm{ppm})$, Cho (3.20, 3.53, and $4.08 \mathrm{ppm}$ ), and $\mathrm{Cr}$ (3.04 and $3.93 \mathrm{ppm})$. We then calculated the following ratios: NAA/Cho, NAA/Cr, and Cho/Cr. ${ }^{36,37}$ The
QUEST algorithm calculates errors associated with the estimated metabolite amplitudes by using an extended version of the Cramer-Rao lower bounds calculation. ${ }^{35}$ The errors for each of the calculated metabolite ratios were derived through error propagation of the jMRUI output.

\section{Data Analysis: Diffusion and sMRI}

Apparent Diffusion Coefficients. ROI analysis was performed on ADC maps by using standard software on the 3T Magnetom Verio MR imaging system (Siemens). First, ROIs within white matter and gray matter were identified from the HASTE images acquired in the same plane and with the same coverage as the diffusion- 


\begin{tabular}{|c|c|c|c|c|c|}
\hline & \multirow[b]{2}{*}{ Control $(n=26)$} & \multicolumn{4}{|c|}{ Diabetes } \\
\hline & & All $(n=26)$ & $\operatorname{GDM}(n=13)$ & $\operatorname{TIDM}(n=12)$ & $\operatorname{T2DM}(n=1)$ \\
\hline \multicolumn{6}{|l|}{ Maternal demographics } \\
\hline Maternal age (mean) (SD) (yr) & $31(5)$ & $31(5)$ & $32(5)$ & $30(6)$ & 34 \\
\hline Parity (median) (range) & $0(0-3)$ & $0(0-3)$ & $1(0-2)$ & $0(0-3)$ & 0 \\
\hline Current smoker (No.) (\%) & $1(4)$ & $3(12)$ & $1(8)$ & $2(17)$ & \\
\hline \multicolumn{6}{|l|}{ Deprivation (No.) (\%) } \\
\hline SIMD 1-3 & $13(50)$ & $13(50)$ & $6(46)$ & $6(50)$ & 1 \\
\hline SIMD 4-5 & $13(50)$ & $13(50)$ & $7(54)$ & $6(50)$ & \\
\hline \multicolumn{6}{|l|}{ MRI details } \\
\hline Gestation at MRI (mean) (SD) (wk) & $36.1(0.9)$ & $36.0(0.8)$ & $36.0(0.8)$ & $36.0(0.9)$ & 36.7 \\
\hline MRI-to-delivery interval (mean) (SD) (wk) & $3.6(1.6)$ & $2.1(1.2)$ & $2.6(1.2)$ & $1.6(1.1)$ & 15 \\
\hline \multicolumn{6}{|l|}{ Neonatal outcome } \\
\hline Gestation delivery (mean) (SD) (wk) & $39.7(1.5)$ & $38.1(1.4)$ & $38.6(1.1)$ & $37.6(1.5)$ & 38.9 \\
\hline Birthweight (mean) (SD) (g) & $3372(467)$ & $3551(627)$ & $3629(483)$ & $3508(780)$ & 3040 \\
\hline Sex (male/female) & 13:13 & 9:17 & $6: 7$ & $2: 10$ & Male \\
\hline Occipitofrontal circumference (mean) (SD) (cm) & $34.4(1.4)$ & $34.8(1.8)$ & $35(1.6)$ & $35(2.2)$ & 36 \\
\hline
\end{tabular}

Note:-SIMD indicates Scottish Index of Multiple Deprivation; SIMD 1, most deprived; SIMD 5, most affluent.

weighted images. A section above the ventricles was identified as white matter, and a section at the level of the thalami was identified as deep gray matter by using landmarks described in Boardman et al. ${ }^{38}$ The identical sections were then identified on the corresponding ADC map; 4 ROIs were positioned in the white matter ( 2 posterior and 2 anterior) and 2 were positioned in the gray matter. Due to differences in fetal brain volume, we used an anatomically appropriate ROI size for each individual brain, taking care to avoid partial volume effects from adjacent structures and artifacts. The mean (SD) ADC value for each ROI was recorded. The mean white matter ROI size was $0.30 \pm 0.12$, and the mean gray matter ROI size was $0.32 \pm 0.13$. Sample ROI placements for white and gray matter are shown in Fig $1 B$. Interrater agreement was checked by 2 independent investigators (D.A., G.M.).

sMRI. For each participant, a single 3D motion-corrected brain volume was reconstructed by using a section-to-volume registration method (Fig 1C). ${ }^{39}$ The fetal brain was extracted from surrounding fetal and maternal tissue by using an atlas-based approach. ${ }^{40}$ All reconstructed images were nonlinearly aligned to the closest age-matched template from a publicly available $4 \mathrm{D}$ fetal brain atlas. ${ }^{41}$ Then, an automatic method based on an expectation-maximization framework for brain tissue segmentation was used, in which the priors of brain tissues were propagated by using prior probabilities provided by the $4 \mathrm{D}$ atlas. Finally, binary masks of the cerebrum (intracranial contents excluding intraventricular CSF, extra-axial CSF, and the choroid plexus, brain stem, cerebellum, and pons structures) and the intracranial volume (GM, WM, and CSF) were deformed to the subject's native space, and volumes were calculated.

\section{Statistical Analysis}

This was a feasibility study, so a formal power calculation for sample size was not required. ${ }^{42,43}$ For normally distributed data, the mean and SD are reported, and for non-normally distributed data, the median and interquartile range are reported. For groupwise comparisons of normally distributed variables, an independent-sample $t$ test was used, and for skewed data, the Mann-Whitney $U$ test was used. To analyze regional ADC values, we first tested for evidence of laterality in the anterior and posterior white matter and deep gray matter values with a paired-samples $t$ test, and if there were no significant differences between left and right, the values were averaged to compute mean anterior white matter $\mathrm{ADC}$, mean posterior white matter ADC, and mean deep gray matter ADC per individual. The distributions were assessed for normality, and an independent-samples $t$ test was used for groupwise comparisons of regional ADC. Interobserver agreement in ADC measurements was assessed for each region in a randomly selected subset of 20 participants by using Bland-Altman statistics. For group-wise analysis of NAA/Cho, NAA/Cr, and Cho/Cr ratios and cerebral and intracranial volumes, an independentsamples $t$ test was used after assessing the equality of variance between groups. Statistical analyses were performed by using SPSS 21 (IBM, Armonk, New York) with statistical significance defined as $P<.05$.

\section{RESULTS \\ Participants}

The maternal demographics and delivery outcomes of the study population are shown in Table 1. All women tolerated the MR imaging well, and no scan had to be abandoned due to maternal discomfort or claustrophobia. Of the women with diabetes, 13 were diagnosed with GDM during pregnancy, 12 had T1DM, and 1 had T2DM. In women with GDM, the median gestation at diagnosis and diagnosis-to-scan interval were 27.1 weeks (interquartile range, 12.0-31.0 weeks) and 8.9 weeks (interquartile range, 4.4-23.6 weeks), respectively. Only 1 woman with GDM was treated with diet alone. The other 12 were treated with metformin $(n=9)$ or metformin and insulin $(n=3)$ to achieve glycemic control. All women with T1DM were insulin-treated, and the 1 woman with T2DM was treated with insulin and metformin. The hemoglobin A1c (glycolated hemoglobin) at booking (11-13 weeks' gestation) for women with T1DM and T2DM was $51.9 \mathrm{mmol} / \mathrm{mol}(16.6 \mathrm{mmol} / \mathrm{mol})$. Two women with GDM, 4 women with T1DM, and 1 control had antenatal steroids for fetal lung maturation before MR imaging. Three neonates of women with T1DM were admitted to the neonatal unit for $<72$ hours. The reasons for admission were suspected sepsis (culture negative 


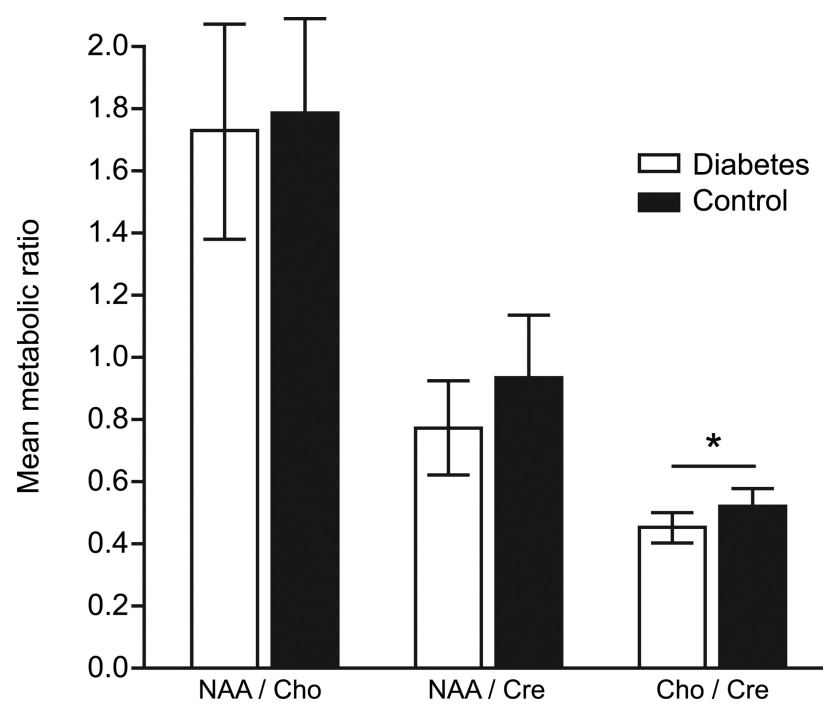

FIG 2. Metabolite ratios for NAA/Cho, NAA/Cr, and Cho/Cr in the fetal brain in women with diabetes and healthy controls. Data are presented as mean $\pm \mathrm{SD}$.

for bacteria) and transient low blood glucose $(n=1)$, a fractured clavicle sustained during a forceps delivery with shoulder dystocia, and a duplication cyst that was not diagnosed antenatally. No neonates born to healthy controls required admission. All neonates were discharged home alive and well.

There was no difference in the gestation in weeks at MR imaging between women with diabetes and healthy controls (mean [SD]) (36.0 weeks [0.8 weeks] versus 36.1 weeks [0.9 weeks], $P=$ .69). No adjustment was therefore made for gestational age in the statistical analysis. No congenital anomalies, acquired brain injuries, or incidental findings were detected by MR imaging.

\section{MR Spectroscopy}

In utero ${ }^{1} \mathrm{H}$-MRS of the fetal brain of suitable quality for analysis was obtained in $41 / 52$ (79\%) women in the study population, $22 / 26(85 \%)$ with diabetes and 19/26 (73\%) healthy controls. There was no difference in the clinical characteristics of women in whom interpretable data were acquired compared with those in whom they were not (data not shown). There was no difference in the NAA/Cho and NAA/Cr ratios in the fetal brain in women with diabetes compared with controls (1.74 [0.70] versus 1.79 [0.64], $P=.81$; and $0.78[0.28]$ versus $0.94[0.36], P=.12$, respectively). The $\mathrm{Cho} / \mathrm{Cr}$ ratio was marginally lower in the fetal brain in women with diabetes compared with controls $(0.46$ [0.11] versus $0.53[0.10], P=.04)$ (Fig 2).

\section{Diffusion-Weighted Imaging: ADC}

DWIs amenable to ADC computation were available for $37 / 52$ (71\%) women in the study population, 18/26 (69\%) with diabetes and $19 / 26(73 \%)$ healthy controls. Fetal motion or maternal size prevented interpretable data from being obtained from 9/52 $(17 \%)$ of the study population. There was no difference in the clinical characteristics of women in whom interpretable data were acquired compared with those in whom they were not (data not shown).

There was no evidence of laterality in the anterior white matter, posterior white matter, or deep gray matter ADC values (all

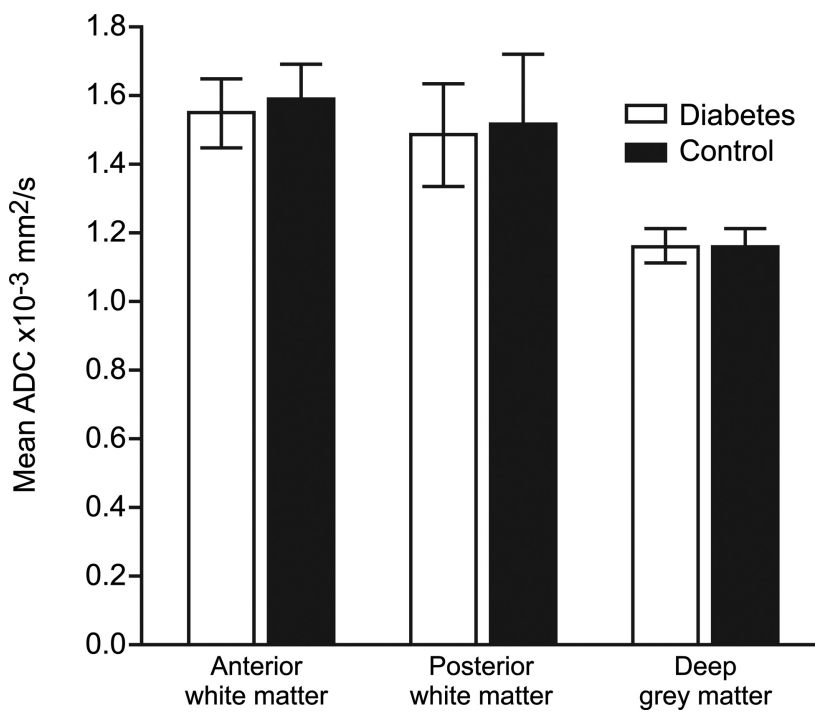

FIG 3. ADC values in the anterior white matter, posterior white matter, and deep gray matter in the fetal brain in women with diabetes and healthy controls. Data are presented as mean \pm SD.

$P>$.05). Data were therefore combined to 3 variables: mean anterior white matter, mean posterior white matter, and mean deep gray matter ADC. There was no difference in mean (SD) $\mathrm{ADC}$ values for anterior white matter, posterior white matter, and deep gray matter in women with diabetes mellitus compared with controls (1.16 [0.12] versus 1.16 [0.08], $P=.96 ; 1.54$ [0.16] versus $1.59[0.20], P=.56$; and $1.49[0.23]$, versus $1.52[0.23], P=.89$, respectively) (Fig 3 ).

There was good interrater agreement between the 2 independent investigators for ADC values. The mean difference and 95\% confidence intervals between investigators for anterior white matter, posterior white matter, and deep gray matter measurements are reported in Table 2 .

\section{Brain Volumes}

Tissue segmentation data suitable for analysis were used to assess the macrostructure of the fetal brain in 24/52 (46\%) of the study population (9/26 [35\%] women with diabetes, 15/26 [58\%] healthy controls). Fetal motion or data quality prevented interpretable data from being obtained from 28/52 (54\%) women of the study population. There was no difference in mean cerebrum volume/milliliter in women with diabetes compared with controls $\left(243.0 \pm 22.7 \mathrm{~mL}^{3}\right.$ versus $\left.253.8 \pm 31.6 \mathrm{~mL}^{3}, P=.39\right)$. There was no difference in mean intracranial volume in fetuses of women with diabetes compared with controls $\left(265.0 \pm 22.5 \mathrm{~mL}^{3}\right.$ versus $\left.274.5 \pm 32.3 \mathrm{~mL}^{3}, P=.47\right)$.

\section{DISCUSSION}

In this study, we demonstrated that it is feasible to recruit pregnant women with diabetes to undergo MR imaging at 3T during the third trimester of pregnancy for measurements of NAA/Cho, $\mathrm{NAA} / \mathrm{Cr}$, and Cho/Cr ratios; regional ADC measurements; and cerebrum and intracranial volumes. We chose to acquire ${ }^{1} \mathrm{H}$ MRS, DWI, and sMRI because of their use as markers of tissue injury/altered metabolism in the neonatal period and their relationships with long-term outcome. The values we acquired con- 
Table 2: Bland-Altman statistics for ADC measurements recorded by 2 observers ${ }^{a}$

\begin{tabular}{lccc}
\hline & Mean Difference & Mean + (1.96 $\times$ SD) & Mean - (1.96 * SD) \\
\hline Gray matter ADC & $-0.073 \times 10^{-3} \mathrm{~mm}^{2} / \mathrm{s}$ & $0.108 \times 10^{-3} \mathrm{~mm}^{2} / \mathrm{s}$ & $-0.253 \times 10^{-3} \mathrm{~mm}^{2} / \mathrm{s}$ \\
Anterior white matter ADC & $-0.033 \times 10^{-3} \mathrm{~mm}^{2} / \mathrm{s}$ & $0.175 \times 10^{-3} \mathrm{~mm}^{2} / \mathrm{s}$ & $-0.241 \times 10^{-3} \mathrm{~mm}^{2} / \mathrm{s}$ \\
Posterior white matter ADC & $-0.028 \times 10^{-3} \mathrm{~mm}^{2} / \mathrm{s}$ & $0.225 \times 10^{-3} \mathrm{~mm}^{2} / \mathrm{s}$ & $-0.281 \times 10^{-3} \mathrm{~mm}^{2} / \mathrm{s}$ \\
\hline
\end{tabular}

${ }^{a}$ Data are presented as mean difference $\pm 95 \%$ confidence intervals $91.96 \times$ SD.

tribute useful normative data for future fetal brain studies performed with $3 \mathrm{~T}$ systems.

Although this feasibility study was not powered to detect group differences, we observed a marginal-but-significant reduction in Cho/Cr in the brains of fetuses of diabetic mothers during the third trimester. The MR spectroscopy choline peak included free choline, phosphocholine, and glycerophosphocholine, so these data raise the possibility that brain metabolism and neuronal membrane phospholipid turn-over are altered in pregnancies with women with diabetes. While this finding requires confirmation in a larger study, alterations in the Cho/Cr ratio in brains of adults with type 2 diabetes have been reported. ${ }^{44}$

A strength of our study is that we recruited a cohort of women with well-characterized diabetes with all participants being scanned within a 4-week time window and gestation matched to our control group. This feature is important because ${ }^{1} \mathrm{H}-\mathrm{MRS}$ spectra and ADC values are dynamic during this period of brain development. ${ }^{45-47}$ We also acquired sMRI suitable for conventional clinical reporting, which was possible for all participants. A limitation of our study is that we were unable to acquire data amenable to quantitative analysis on all fetuses scanned. Despite ensuring the comfort of the women in a large-bore scanner, data could not be processed from ${ }^{1} \mathrm{H}$-MRS in $21 \%$ of cases: DWI in $29 \%$ of cases and sMRI in $54 \%$ of cases. The low data yield for sMRI was partly because acquisition of ${ }^{1} \mathrm{H}-\mathrm{MRS}$ and DWI was prioritized over sMRI. For future study designs that require fetal brain segmentation, yield may be increased by modifications to the acquisition protocol such as the increasing the number of stacks per plane and accepting the idea that time constraints required for safety may curtail other acquisitions (we capped imaging at 45 minutes). sMRI suitable for conventional clinical reporting was available for all participants.

We chose to recruit a heterogeneous population of women with diabetes to assess the feasibility of dissecting the effect of different in utero exposure to T1DM, T2DM, and GDM in a future study. Recruitment of women with T1DM and GDM was relatively easy; thus, recruitment to a future study assessing the effect of in utero exposure of T1DM and GDM on the fetal brain would be feasible. In contrast, we were able to recruit only 1 woman with T2DM, due to the lower prevalence of this condition. Thus, targeting recruitment of women with T2DM to a future study will not be practical unless recruitment occurs across multiple sites.

Our data were acquired by using a 3T system as opposed to 1.5T. For the advanced imaging techniques used in this study, there are advantages of acquiring data with the higher field strength of $3 \mathrm{~T} .{ }^{48}$ Compared with lower field strengths, imaging at higher field strengths increases the signal-to-noise ratio. This increase improves the spectral quality obtained in ${ }^{1} \mathrm{H}-\mathrm{MRS}$ and the ability to differentiate closely located metabolites, particularly at short TEs. The inability to complete data acquisition within the time available due to fetal movement is a major limitation of MR imaging in pregnancy. Acquiring data more rapidly by using more advanced imaging methodologies, using methods of motion correction to compensate for fetal movement, and using alternative sampling techniques such as compressed sensing is likely to greatly increase data yield in the future. Finally, one advantage of $3 \mathrm{~T}$ is the ability to acquire images with higher spatial resolution (depending on the imaging coil used), potentially increasing diagnostic accuracy. ${ }^{49}$

Perinatal image metrics are sensitive to tissue injury and neuroprotective treatment strategies. They are therefore increasingly used to address the "gap in translation" in perinatal neuroscience to assess therapies that show promise in preclinical studies at lower economic and opportunity costs than randomized controlled trials powered on clinical outcomes. ${ }^{50}$ The normative data provided here may inform the development of fetal brain biomarkers for use in interventional perinatal neuroprotective outcome studies.

\section{CONCLUSIONS}

The data provide proof-of-concept that comprehensive assessment of the fetal brain using measures derived from images acquired at $3 \mathrm{~T}$ from women with diabetes and healthy controls is achievable. In addition, they suggest that fetal brain MR spectroscopy may provide a promising image marker of altered brain development in maternal diabetes. Finally, although we studied fetuses of mothers with diabetes, this research pipeline and the normative values obtained could be applied to any paradigm in which fetal origins of brain development are being investigated by using 3T MR imaging.

\section{ACKNOWLEDGMENTS}

We are grateful to the women who consented to take part in the study, to the research midwives, and to the nursing and radiography staff at the Clinical Research Imaging Centre, University of Edinburgh (http://www.cric.ed.ac.uk) who participated in scanning the women.

Disclosures: Fiona C. Denison—RELATED: Grant: TheirWorld, Comments: block grant, research funded by TheirWorld to cover work undertaken and reported in the article*; UNRELATED: Board Membership: Vice-Chair of the National Institute of Clinical Excellence Committee, Comments: I am Vice-Chair of the National Institute of Clinical Excellence Medical Technologies Advisory Committee. My travel expenses are paid to attend this monthly meeting. I am not paid directly to attend; Grants/Grants Pending: National Institute for Health and Care Excellence, Medical Research Council, Edinburgh and Lothians Health Foundation, and Tommy's, Comments: I am Co-Investigator or Principal Investigator of several research grants funded by the National Institute for Health and Care Excellence, Medical Research Council, Edinburgh, and Lothians Health Foundation. All of these grants fund separate studies, and there is no overlap with the work undertaken in article. Gillian Macnaught-UNRELATED: Employment: GlaxoSmithKline, Comments: Forty percent of my previous post was paid by GlaxoSmithKline; however, they were not involved in this submitted work.* Scott I.K. Semple-UNRELATED: Other: GlaxoSmithKline, Comments: GlaxoSmithKline sponsored a research fellow in my group, not connected to this work.* Jane 
Walker—RELATED: Grant: TheirWorld.* James P. Boardman—RELATED: Grant: TheirWorld. * * Money paid to the institution.

\section{REFERENCES}

1. Mitanchez D, Yzydorczyk C, Siddeek B, et al. The offspring of the diabetic mother: short- and long-term implications. Best Pract Res Clin Obstet Gynaecol 2015;29:256-69 CrossRef Medline

2. Bolaños L, Matute E, Ramírez-Dueñas Mde L, et al. Neuropsychological impairment in school-aged children born to mothers with gestational diabetes. J Child Neurol 2015;30:1616-24 CrossRef Medline

3. Stehbens JA, Baker GL, Kitchell M. Outcome at ages 1, 3, and 5 years of children born to diabetic women. Am J Obstet Gynecol 1977;127: 408-13 CrossRef Medline

4. Nomura Y, Marks DJ, Grossman B, et al. Exposure to gestational diabetes mellitus and low socioeconomic status: effects on neurocognitive development and risk of attention-deficit/hyperactivity disorder in offspring. Arch Pediatr Adolesc Med 2012;166:337-43 CrossRef Medline

5. Temple RC, Hardiman M, Pellegrini M, et al. Cognitive function in 6- to 12-year-old offspring of women with Type 1 diabetes. Diabet Med 2011;28:845-48 CrossRef Medline

6. Dionne G, Boivin M, Séguin JR, et al. Gestational diabetes hinders language development in offspring. Pediatrics 2008;122:e1073-79 CrossRef Medline

7. Kalhan S, Parimi P. Gluconeogenesis in the fetus and neonate. Semin Perinatol 2000;24:94-106 CrossRef Medline

8. Pagán A, Prieto-Sánchez MT, Blanco-Carnero JE, et al. Materno-fetal transfer of docosahexaenoic acid is impaired by gestational diabetes mellitus. Am J Physiol Endocrinol Metab 2013;305:E826-33 CrossRef Medline

9. Larqué E, Demmelmair H, Gil-Sánchez A, et al. Placental transfer of fatty acids and fetal implications. Am J Clin Nutr 2011;94(6 suppl): 1908S-13S CrossRef Medline

10. Limperopoulos C, Tworetzky W, McElhinney DB, et al. Brain volume and metabolism in fetuses with congenital heart disease: evaluation with quantitative magnetic resonance imaging and spectroscopy. Circulation 2010;121:26-33 CrossRef Medline

11. Hoffmann C, Grossman R, Bokov I, et al. Effect of cytomegalovirus infection on temporal lobe development in utero: quantitative MRI studies. Eur Neuropsychopharmacol 2010;20:848-54 CrossRef Medline

12. Erdem G, Celik O, Hascalik S, et al. Diffusion-weighted imaging evaluation of subtle cerebral microstructural changes in intrauterine fetal hydrocephalus. Magn Reson Imaging 2007;25:1417-22 CrossRef Medline

13. Pier DB, Levine D, Kataoka ML, et al. Magnetic resonance volumetric assessments of brains in fetuses with ventriculomegaly correlated to outcomes. J Ultrasound Med 2011;30:595-603 CrossRef Medline

14. Egaña-Ugrinovic G, Sanz-Cortes M, Figueras F, et al. Fetal MRI insular cortical morphometry and its association with neurobehavior in late-onset small-for-gestational-age fetuses. Ultrasound Obstet Gynecol 2014;44:322-29 CrossRef Medline

15. Masoller N, Sanz-Cortés M, Crispi F, et al. Severity of fetal brain abnormalities in congenital heart disease in relation to the main expected pattern of in utero brain blood supply. Fetal Diagn Ther 2016;39:269-78 CrossRef Medline

16. Sanz Cortes M, Bargallo N, Arranz A, et al. Feasibility and success rate of a fetal MRI and MR spectroscopy research protocol performed at term using a 3.0-Tesla scanner. Fetal Diagn Ther 2016 May 27. [Epub ahead of print] CrossRef Medline

17. Sanz-Cortes M, Egaña-Ugrinovic G, Simoes RV, et al. Association of brain metabolism with sulcation and corpus callosum development assessed by MRI in late-onset small fetuses. Am J Obstet Gynecol 2015;212:804 e1-8 CrossRef Medline

18. Sanz-Cortes M, Simoes RV, Bargallo N, et al. Proton magnetic resonance spectroscopy assessment of fetal brain metabolism in late- onset 'small for gestational age' versus 'intrauterine growth restriction' fetuses. Fetal Diagn Ther 2015;37:108-16 CrossRef Medline

19. Simões RV, Sanz-Cortes M, Muñoz-Moreno E, et al. Feasibility and technical features of fetal brain magnetic resonance spectroscopy in 1.5 T scanners. Am J Obstet Gynecol 2015;213:741-42 CrossRef Medline

20. Taylor-Clarke M. Re: mid-gestation brain Doppler and head biometry in fetuses with congenital heart disease predict abnormal brain development at birth. N. Masoller, M. Sanz-Cortés, F. Crispi, O. Gómez, M. Bennasar, G. Egaña-Ugrinovic, N. Bargalló, J. M. Martínez and E. Gratacós. Ultrasound Obstet Gynecol 2016; 47: 6573. Ultrasound Obstet Gynecol 2016;47:15 CrossRef Medline

21. Victoria T, Johnson AM, Edgar JC, et al. Comparison between 1.5-T and 3-T MRI for fetal imaging: is there an advantage to imaging with a higher field strength? AJR Am J Roentgenol 2016;206:195-201 CrossRef Medline

22. Van Kooij BJ, Benders MJ, Anbeek P, et al. Cerebellar volume and proton magnetic resonance spectroscopy at term, and neurodevelopment at 2 years of age in preterm infants. Dev Med Child Neurol 2012;54:260-66 CrossRef Medline

23. Hanrahan JD, Cox IJ, Azzopardi D, et al. Relation between proton magnetic resonance spectroscopy within 18 hours of birth asphyxia and neurodevelopment at 1 year of age. Dev Med Child Neurol 1999; 41:76-82 CrossRef Medline

24. Amess PN, Penrice J, Wylezinska M, et al. Early brain proton magnetic resonance spectroscopy and neonatal neurology related to neurodevelopmental outcome at 1 year in term infants after presumed hypoxic-ischaemic brain injury. Dev Med Child Neurol 1999; 41:436-45 Medline

25. Filippi CG, Uluğ AM, Deck MD, et al. Developmental delay in children: assessment with proton MR spectroscopy. AJNR Am J Neuroradiol 2002;23:882-88 Medline

26. Counsell SJ, Allsop JM, Harrison MC, et al. Diffusion-weighted imaging of the brain in preterm infants with focal and diffuse white matter abnormality. Pediatrics 2003;112(1 pt 1):1-7 CrossRef Medline

27. Cavalleri F, Lugli L, Pugliese M, et al. Prognostic value of diffusionweighted imaging summation scores or apparent diffusion coefficient maps in newborns with hypoxic-ischemic encephalopathy. Pediatr Radiol 2014;44:1141-54 CrossRef Medline

28. Rutherford M, Biarge MM, Allsop, et al. MRI of perinatal brain injury. Pediatr Radiol 2010;40:819-33 CrossRef Medline

29. Boardman JP, Counsell SJ, Rueckert D, et al. Early growth in brain volume is preserved in the majority of preterm infants. Ann Neurol 2007;62:185-92 CrossRef Medline

30. Inder TE, Warfield SK, Wang H, et al. Abnormal cerebral structure is present at term in premature infants. Pediatrics 2005;115:286-94 CrossRef Medline

31. Boardman JP, Craven C, Valappil S, et al. A common neonatal image phenotype predicts adverse neurodevelopmental outcome in children born preterm. Neuroimage 2010;52:409-14 CrossRef Medline

32. Ullman H, Spencer-Smith M, Thompson DK, et al. Neonatal MRI is associated with future cognition and academic achievement in preterm children. Brain 2015;138(pt 11):3251-62 CrossRef Medline

33. Scottish Intercollegiate Guidelines Network. Management of diabetes: a national clinical guideline, 2014. Edinburgh. http://www.sign.ac.uk/pdf/ sign116.pdf. Accessed May 30, 2016

34. Macnaught G, Gray C, Walker J, et al. (1)H MRS: a potential biomarker of in utero placental function. NMR Biomed 2015;28: 1275-82 CrossRef Medline

35. Ratiney H, Sdika M, Coenradie Y, et al. Time-domain semi-parametric estimation based on a metabolite basis set. NMR Biomed 2005; 18:1-13 CrossRef Medline

36. Horton MK, Margolis AE, Tang C, et al. Neuroimaging is a novel tool to understand the impact of environmental chemicals on neurodevelopment. Curr Opin Pediatr 2014;26:230-36 CrossRef Medline

37. Spader HS, Ellermeier A, O’Muircheartaigh J, et al. Advances in myelin imaging with potential clinical application to pediatric imaging. Neurosurg Focus 2013;34:E9 CrossRef Medline 
38. Boardman JP, Counsell SJ, Rueckert D, et al. Abnormal deep grey matter development following preterm birth detected using deformation-based morphometry. Neuroimage 2006;32:70-78 CrossRef Medline

39. Rousseau F, Oubel E, Pontabry J, et al. BTK: an open-source toolkit for fetal brain MR image processing. Comput Methods Programs Biomed 2013;109:65-73 CrossRef Medline

40. Serag A, Aljabar P, Ball G, et al. Construction of a consistent highdefinition spatio-temporal atlas of the developing brain using adaptive kernel regression. Neuroimage 2012;59:2255-65 CrossRef Medline

41. Serag A, Kyriakopoulou V, Rutherford MA, et al. A multi-channel 4D probabilistic atlas of the developing brain: application to fetuses and neonates. Ann BMVA 2012;2012:1-14. http://www.bmva.org/annals/ 2012/2012-0003.pdf

42. Billingham SA, Whitehead AL, Julious SA. An audit of sample sizes for pilot and feasibility trials being undertaken in the United Kingdom registered in the United Kingdom Clinical Research Network database. BMC Med Res Methodol 2013;13:104 CrossRef Medline

43. Whitehead AL, Julious SA, Cooper CL, et al. Estimating the sample size for a pilot randomised trial to minimise the overall trial sample size for the external pilot and main trial for a continuous outcome variable. Stat Methods Med Res 2016;25:1057-73 CrossRef Medline

44. Santhakumari R, Reddy IY, Archana R. Effect of type 2 diabetes mel- litus on brain metabolites by using proton magnetic resonance spectroscopy: a systematic review. Int J Pharma Bio Sci 2014;5: 1118-23 Medline

45. Cannie M, De Keyzer F, Meersschaert J, et al. A diffusion-weighted template for gestational age-related apparent diffusion coefficient values in the developing fetal brain. Ultrasound Obstet Gynecol 2007; 30:318-24 CrossRef Medline

46. Kok RD, van den Berg PP, van den Bergh AJ, et al. Maturation of the human fetal brain as observed by 1 H MR spectroscopy. Magn Reson Med 2002;48:611-16 CrossRef Medline

47. Righini A, Bianchini E, Parazzini C, et al. Apparent diffusion coefficient determination in normal fetal brain: a prenatal MR imaging study. AJNR Am J Neuroradiol 2003;24:799-804 Medline

48. Wardlaw JM, Brindle W, Casado AM, et al; SINAPSE Collaborative Group. A systematic review of the utility of 1.5 versus 3 Tesla magnetic resonance brain imaging in clinical practice and research. Eur Radiol 2012;22:2295-303 CrossRef Medline

49. Alvarez-Linera J. 3T MRI: advances in brain imaging. Eur J Radiol 2008;67:415-26 CrossRef Medline

50. Azzopardi D, Robertson NJ, Bainbridge A, et al. Moderate hypothermia within $6 \mathrm{~h}$ of birth plus inhaled xenon versus moderate hypothermia alone after birth asphyxia (TOBY-Xe): a proof-of-concept, open-label, randomised controlled trial. Lancet Neurol 2015 Dec 18. [Epub ahead of print] CrossRef Medline 